\title{
Environmental Pollution Evaluation of Urban Rail Transit Construction Based on Entropy Weight Method
}

\author{
Yang Yin* and Yu Zhang**† \\ *School of Management, Wuhan University of Technology, Wuhan 430070, China \\ **School of Economics \& Management, Hubei University of Arts and Science, Xiangyang 441000, China \\ †Corresponding author: Yu Zhang: hbuaszy@163.com
}

Nat. Env. \& Poll. Tech.

Website: www.neptjournal.com

Received: 12-11-2020

Revised: 24-03-2021

Accepted: 12-05-2021

\section{Key Words:}

Urban rail transit

Environmental pollution

Entropy weight method

Evaluation index system

\begin{abstract}
With the development of cities, urban rail transit has entered into a stage of rapid construction and development, but the environmental pollution caused by rail transit construction cannot be ignored. To evaluate the environmental pollution of urban rail transit construction, an evaluation system for the environmental pollution induced by urban rail transit construction was established by using the literature survey method and the entropy weight method. The evaluation index system involved three first-level indicators of the physical environment, natural environment and social environment, and 11 second-level indicators. The impact of XA-XDM project construction on urban environmental pollution in Wuhan, China was evaluated by using the evaluation system. Results show that the evaluation score of XA-XDM project is 76.5, which means that the XA-XDM project construction has a strong impact on environmental pollution. It should be paid to the prevention, control and monitoring of various pollution indicators, reducing environmental pollution, and realizing green construction.
\end{abstract}

\section{INTRODUCTION}

Urban rail transit is the main transportation mode currently promoted, and its construction will inevitably pass through transportation hubs such as urban arterial roads, prosperous business districts and densely populated areas. However, the construction of urban rail transit projects needs a long period and is on large scale. Construction in existing transportation hub areas unavoidably faces difficulties such as a harsh construction environment and narrow working space. Meanwhile, the construction process inevitably creates a great deal of pollution to the existing urban environment (Wang 2019). Relevant studies reveal that the environmental pollution caused by urban construction has become more and more serious (Wang et al. 2015, Wang et al. 2015). For example, the frequent urban smog pollution in recent years has mainly occurred in major cities. Contrarily, such pollution in small cities is relatively light. The main pollution source generates from the construction of urban buildings and the continuous expansion of the scale of municipal public construction. These constructions have caused dust, exhaust gas in the air, noise pollution and vegetation destruction, increasing pollution sources and exceeding the city's ecological self-purification ability (Xue et al. 2017). Data show that there were more than 500,000 complaints about environmental pollution in China in 2018, accounting for $35.3 \%$ of the total complaints, while the number of noise pollution cases caused by construction reached $46.1 \%$, which is the largest proportion (Ministry of Environmental Protection of the People's Republic of China 2018).

Due to the complex construction environments, the environmental pollution caused by urban rail construction is difficult to be evaluated. Therefore, how to evaluate the pollution degree of construction to the environment is important to control the construction process, and then adopting targeted measures to reduce environmental pollution and improving the urban environment. It is of great significance to realize the green construction of urban rail transit and the sustainable development of urban construction.

\section{EARLIER STUDIES}

As the country attaches importance to environmental protection, people's awareness of urban environmental protection has been continuously improved. The pollution of the urban environment caused by construction has attracted widespread attention from all walks of life. Requirements and guidance on environmental aspects of rail transit construction have been made by "Notice on Doing a Good Job in Environmental Impact Assessment of Urban Rail Transit Projects (2014)" and "Technical Specification for Environmental Vibration and Noise Control Engineering of Urban Rail Transit (HJ2055-2018)" issued by the Ministry 
of Environmental Protection and the Ministry of Ecology and Environment, respectively.

Concerning the research on air pollution caused by urban rail transit construction, Huang et al. (2007) compared and analyzed the environmental pollution caused by construction in different construction stages. The results showed that excavation and construction can cause more environmental pollution than other stages. Li et al. (2014) used point monitoring TSP to achieve the monitoring of work areas, construction sheds and roadsides, and found that the earth and stone cause the most serious dust pollution to the environment. Hala et al. (2015) applied the dust concentration prediction model (FDM) to monitor the fugitive dust and particulate matter on the construction site in Doha, Qatar, and the results showed that the FDM simulation can determine the characteristics of fugitive dust pollution.

Regarding the research on noise pollution caused by urban rail transit construction, Bowlby studied the construction noise of high-speed rail construction projects, abstracting the noise source into points, lines, and surfaces, and considering the attenuation and propagation of noise by sound insulation panels (Haron et al. 2009). Based on the above conditions, a noise simulation model was finally established. Wang et al. (2018) analyzed environmental noise monitoring and evaluation methods in China, Japan, the European Union and the United States. Liu (2005) monitored the noise at the boundary of the construction project, and the results showed that the noise pollution to the surrounding environment during the piling stage was serious, which even affects the health of surrounding residents. Zhang (2013) used noise simulation software to analyze the impact of loaders, rammers, and vibration-impact ramming on the noise pollution and pointed out the largest noise source.

Considering the land subsidence caused by urban rail transit construction, Yang et al. (2013) used the finite element software MIDAS to simulate the track excavation project in the Wuhan rail transit project. The influence of track excavation on the ground settlement was studied. Meng et al. (2016) used the finite element software ANSYS to analyze the effect of track excavation on the impact of ground subsidence in the Qingdao rail transit project. Zhang (2021) analyzed the construction of Hefei Rail Transit Line 6 and Line 8 and found that the installation of urban rail transit has a non-negligible impact on ground settlement and surrounding buildings.

Studies on the vibration pollution caused by urban rail transit construction indicate that noise and vibration are mainly caused by the driving process of rail vehicles such as trains, subways, and light rails. They result from the collision between the wheels and the track and the mutual transmission of the power unit of the locomotive. Long-term noise interference can cause headache, dizziness, tinnitus, irritability, irritability, insomnia, neurasthenia, etc. (Yang 2011). Continuous vibrations cause the human brain to reduce the level of arousal, distracted, and have difficulty in spatial orientation, damaging mental function. Hu (2020) took the construction of the Chongqing subway as the main research object and conducted effective investigations on the vibration pollution caused by it with different prevention methods to provide a reference for environmental governance.

The pollution of land subsidence, air pollution, vibration pollution and urban landscape caused by urban rail transit construction has become an urgent problem to be solved in the process of urban civilization construction. This is not only related to the daily life of citizens but also concerned the image of the city. This is the core issue of this study.

\section{MATERIALS AND METHODS}

\section{Environmental Pollution Evaluation Index System}

With the demand for transportation in urban development, more and more long-term requirements have been put forward for the planning and design of urban rail transit, such as long routes, multiple lines, and large intersections. The development of rails needs to not only meet the transportation requirement of the city centre, but also consider the development of the suburbs, and even take into account the development of surrounding satellite cities. The construction methods for urban rail transit are different in various construction sites. Underground construction is mostly used in urban centres, while ground construction is mainly employed in suburban areas. Different construction methods cause different pollution to the surrounding environment. Xue et al. (2018) analyzed the pollution to the ecological and natural environment caused by rail transit construction. It showed that construction and excavation damage surrounding vegetation, muck transfer generates dust, and foundation pit construction causes soil settlement and other pollution. Zhu (2018) pointed out that the negative environmental pollution caused by rail transit construction involves noise, water, atmosphere, vibration, and residents' health quality. Zhang et al. (2020) constructed environmental pollution indicators of hydropower projects from the natural, social and ecological environment. The weights of 14 pollution indicators were also analyzed based on probabilistic language close to entropy, and scientific suggestions for project selection was provided.

According to Guan (2018), the environmental pollution caused by urban rail transit construction involves water and soil pollution, vegetation destruction, agricultural ecology, land subsidence, water pollution, air pollution, solid waste, 
Table 1: Environmental Impact Assessment Index system of urban rail transit construction.

\begin{tabular}{|c|c|c|c|}
\hline Target layer & First-level index & Second-level index & Meaning \\
\hline \multirow{11}{*}{$\begin{array}{l}\text { Environmental } \\
\text { Pollution } \\
\text { Assessment of } \\
\text { Urban Rail Transit } \\
\text { Construction } \\
\text { A }\end{array}$} & \multirow[t]{3}{*}{ Ecosystem B1 } & $\begin{array}{l}\text { Water and soil pollution } \\
\text { C1 }\end{array}$ & $\begin{array}{l}\text { Pollution of groundwater caused by cement and chemical grout during } \\
\text { construction }\end{array}$ \\
\hline & & Vegetation destruction $\mathrm{C} 2$ & $\begin{array}{l}\text { Ground excavation and ground track erection damage surrounding } \\
\text { vegetation }\end{array}$ \\
\hline & & Agricultural ecology C3 & Damage to farmland caused by rail transit route planning \\
\hline & \multirow[t]{4}{*}{$\begin{array}{l}\text { Natural } \\
\text { environment B2 }\end{array}$} & Ground subsidence $\mathrm{C} 4$ & $\begin{array}{l}\text { Excavation of underground rail transit lines and excavation of station } \\
\text { foundation pits cause deformation and settlement of roads and surround- } \\
\text { ing buildings }\end{array}$ \\
\hline & & Water pollution $\mathrm{C} 5$ & $\begin{array}{l}\text { Engineering wastewater from construction operations, cleaning wastewater } \\
\text { from construction machinery, domestic wastewater from construction } \\
\text { workers, etc. }\end{array}$ \\
\hline & & Air pollution $\mathrm{C} 6$ & $\begin{array}{l}\text { During the construction process, the dust generated by vehicles entering } \\
\text { and exiting, earth excavation and backfilling, and the fuel exhaust gas } \\
\text { generated by mechanical equipment and vehicles }\end{array}$ \\
\hline & & Solid Waste C7 & $\begin{array}{l}\text { Waste soil, waste rock and construction waste generated during con- } \\
\text { struction }\end{array}$ \\
\hline & \multirow[t]{4}{*}{$\begin{array}{l}\text { Social } \\
\text { environmental } \\
\text { pollution B3 }\end{array}$} & Sound pollution $\mathrm{C} 8$ & $\begin{array}{l}\text { The sound produced by the mechanical equipment and construction } \\
\text { process during the construction, which has an interference effect on the } \\
\text { surrounding residents }\end{array}$ \\
\hline & & Vibration pollution C9 & $\begin{array}{l}\text { Vibration generated during the construction of large engineering equip- } \\
\text { ment, shock vibration generated by blasting }\end{array}$ \\
\hline & & City view C10 & $\begin{array}{l}\text { The impact of construction on the scale, vision and aesthetics of the original } \\
\text { urban space occupation, construction enclosure, and exposed buildings }\end{array}$ \\
\hline & & Population health C11 & $\begin{array}{l}\text { The impact of urban rail transit construction on the work, travel, daily life } \\
\text { and rest of the surrounding residents }\end{array}$ \\
\hline
\end{tabular}

noise pollution, vibration pollution, urban landscape and population health, etc. Moreover, further categorization of the various pollution indicators can result in environmental pollution involving the ecological, natural and social environment. This paper summarizes and sorts out the environmental impact evaluation index system of urban rail transit construction, as given in Table 1.

\section{Evaluation Model}

Entropy is originally a thermodynamic concept. In 1948, Shannon introduced information theory based on the principle of entropy, which was used to describe and measure the degree of disorder in a system. The description of the degree of system order is information. So, the increase or decrease of information is inversely proportional to entropy. Richer information means less entropy. The entropy weight method is a method of calculating indicator weights by objectively assigning weights. According to the degree of variation of selected indicators, a matrix is established, and the threshold method is used to non-dimensionalize the matrix to calculate the information entropy, and then obtain the entropy weight through the difference coefficient ( $L u \&$ Liu 2021). The detailed steps are as follows:
Firstly, the evaluation index and evaluation object are digitized, and the original matrix $X$ is established. The evaluation target $M_{i}(\mathrm{I}=1,2,3, \cdots, \mathrm{m})$ is the row of the matrix, the evaluation index $N_{j}(j=1,2,3, \cdots, \mathrm{n})$ is the column of the matrix, and $X_{i j}$ is the $M_{i}$ evaluation The value of the $N_{j}$ index of the object.

$$
X=\left[\begin{array}{cccc}
x_{11} & x_{12} & \ldots & x_{1 n} \\
x_{21} & x_{22} & \ldots & x_{2 n} \\
\ldots & \ldots & \ldots & \ldots \\
x_{m 1} & x_{m 2} & \ldots & x_{m n}
\end{array}\right]
$$

Secondly, it should be considered that there are differences in dimensions of different orders of magnitude in the original matrix. When this situation occurs, matrix $X$ should be non-dimensionalized so that the value of $X_{i j}$ is in the range of $0 \sim 1$.

Positive dimensionless:

$$
X_{i j}=\frac{x_{i j}-\min \left(x_{j}\right)}{\max \left(r_{j}\right)-\min \left(r_{j}\right)}
$$

Negative dimensionless: 


$$
X_{i j}=\frac{\min \left(x_{j}\right)-x_{i j}}{\max \left(r_{j}\right)-\min \left(r_{j}\right)}
$$

Calculate the weight of each index $X_{i j}$ :

$$
P_{i j}=X_{i j} / \sum_{i=1}^{m} X_{i j}
$$

Get the entropy value of each index $X_{i j}$

$$
e_{i j}=-1 / \ln (m) \sum_{i=1}^{m} P_{i j} \ln P_{i j}
$$

Finally, calculate the entropy weight $W_{j}$

$$
W_{j}=\left(1-e_{i j}\right) / \sum_{j=1}^{n} d_{j}
$$

\section{RESULTS ANALYSIS AND DISCUSSION}

\section{Project Background}

The XA-XDM project belongs to a bid section of XA Rail Transit Line 10 in Wuhan, China. The XDM station of the project is located at Fortune Plaza in the city centre of Wuhan, surrounded by facilities such as Fortune Plaza, parks, office buildings and residential areas, as shown in Fig. 1.

Taking into account the particularity of the project location, it is necessary to evaluate the environmental pollution during the construction period before the project construction, analyze the weight of each index, and help the project make the best construction plan. To ensure the scientific and fair evaluation, many experts and citizen representatives were invited to make an evaluation team to score 11 evaluation indicators. The evaluation involves the magnitude of the impact on each indicator, and the impact is "Very big", "Larger", "General", "Smaller" and

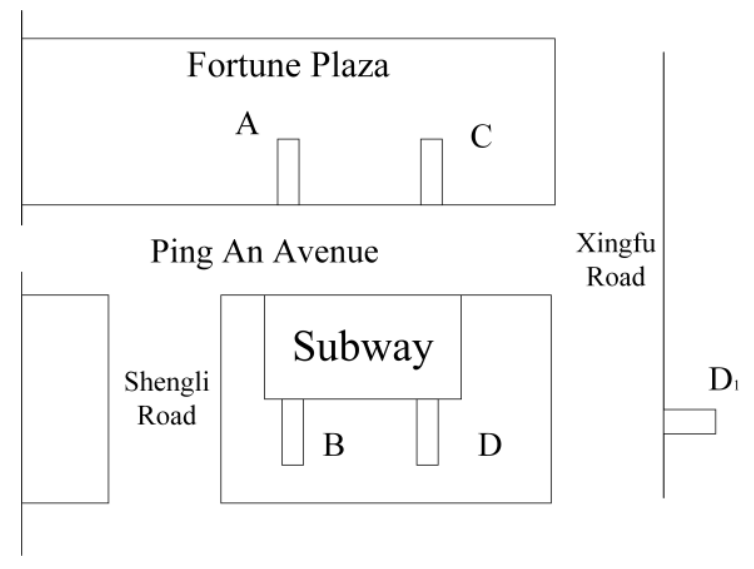

Fig. 1: Schematic diagram of XDM station.

"Very small". By recovering the evaluation data to form the original matrix $X$ and using formulas (1)-(3) to nondimensionalize and normalize the collected data, we obtain the environmental pollution of each indicator. The evaluation results are shown in Table 2.

\section{Analysis of the Weight of Environmental Pollution Index}

Based on the evaluation results of environmental pollution by various indicators, the entropy weight method is used to calculate the entropy value and entropy weight of the standardized matrix. Formulas (4) and (5) are used to obtain the entropy weight of environmental pollution indicators, as shown in Table 3.

The entropy weight results show that the environmental

\begin{tabular}{|c|c|c|c|c|c|c|c|}
\hline \multirow[t]{2}{*}{ Target layer } & \multirow[t]{2}{*}{ First-level index } & \multirow[t]{2}{*}{ Second-level index } & \multicolumn{5}{|c|}{ Environmental pollution assessment } \\
\hline & & & Very big & Larger & General & Smaller & Very small \\
\hline \multirow{11}{*}{$\begin{array}{l}\text { Environmental } \\
\text { Pollution Assessment } \\
\text { of Urban Rail Transit } \\
\text { Construction A }\end{array}$} & \multirow[t]{3}{*}{ Ecosystem B1 } & Water and soil pollution $\mathrm{C} 1$ & 0.06 & 0.06 & 0.19 & 0.30 & 0.40 \\
\hline & & Vegetation destruction $\mathrm{C} 2$ & 0.15 & 0.20 & 0.10 & 0.30 & 0.25 \\
\hline & & Agricultural ecology C3 & 0.03 & 0.20 & 0.40 & 0.25 & 0.12 \\
\hline & \multirow{4}{*}{$\begin{array}{l}\text { Natural } \\
\text { environment B2 }\end{array}$} & Ground subsidence C4 & 0.70 & 0.20 & 0.05 & 0.03 & 0.02 \\
\hline & & Water pollution C5 & 0.45 & 0.30 & 0.15 & 0.08 & 0.02 \\
\hline & & Air pollution $\mathrm{C} 6$ & 0.45 & 0.40 & 0.09 & 0.05 & 0.02 \\
\hline & & Solid waste C7 & 0.20 & 0.40 & 0.30 & 0.06 & 0.04 \\
\hline & \multirow{4}{*}{$\begin{array}{l}\text { Social } \\
\text { environmental } \\
\text { pollution B3 }\end{array}$} & Sound pollution $\mathrm{C} 8$ & 0.25 & 0.48 & 0.10 & 0.13 & 0.05 \\
\hline & & Vibration pollution C9 & 0.35 & 0.45 & 0.10 & 0.05 & 0.05 \\
\hline & & City view C10 & 0.35 & 0.40 & 0.15 & 0.05 & 0.05 \\
\hline & & Population health $\mathrm{C} 11$ & 0.25 & 0.25 & 0.40 & 0.05 & 0.05 \\
\hline
\end{tabular}
pollution indicators of the project's XDM station construction are ranked as land subsidence, air pollution, vibration

Table 2: Evaluation results of the project's environmental impact assessment indicators. 
Table 3: Entropy weight of environmental pollution indicators.

\begin{tabular}{|c|c|c|c|c|}
\hline Target layer & First-level index & Weights & Second-level index & Weights \\
\hline \multirow{11}{*}{$\begin{array}{l}\text { Environmental Pollution Assessment } \\
\text { of Urban Rail Transit Construction A }\end{array}$} & \multirow[t]{3}{*}{ Ecosystem B1 } & \multirow[t]{3}{*}{0.1533} & Water and soil pollution $\mathrm{C} 1$ & 0.0719 \\
\hline & & & Vegetation destruction $\mathrm{C} 2$ & 0.0189 \\
\hline & & & Agricultural ecology C3 & 0.0625 \\
\hline & \multirow[t]{4}{*}{ Natural environment B2 } & \multirow[t]{4}{*}{0.5083} & Ground subsidence C4 & 0.2050 \\
\hline & & & Water pollution $\mathrm{C} 5$ & 0.0943 \\
\hline & & & Air pollution C6 & 0.1327 \\
\hline & & & Solid waste C7 & 0.0763 \\
\hline & \multirow{4}{*}{$\begin{array}{l}\text { Social environmental pol- } \\
\text { lution B3 }\end{array}$} & \multirow[t]{4}{*}{0.3385} & Sound pollution $\mathrm{C} 8$ & 0.0783 \\
\hline & & & Vibration pollution C9 & 0.1026 \\
\hline & & & City view C10 & 0.0847 \\
\hline & & & Population health C11 & 0.0728 \\
\hline
\end{tabular}

pollution, water pollution, urban landscape pollution, noise pollution, solid waste, population health, and water and soil pollution. It indicates that the most serious environmental pollution caused by rail transit construction in the city centre is ground subsidence $(0.2050)$. The reason is that since the urban centre construction has been completed, the newly constructed rail transit inevitably damages and affects the original urban structure. The project needs to focus on construction to protect the surrounding structure, reduce the impact on ground settlement, and restore the damaged environment after the construction is completed. Among the environmental pollution indicators, the urban landscape (0.0847) is ranked in the top five, indicating that in the current urban development, urban landscapes also attract a lot of attention. The construction of urban rail transit in the city centre should pay full attention to match the original urban landscape. The impact of enclosure and work area on the urban environment during the construction should also take into account. The image of the city should not be ignored during rapid construction. Moreover, air pollution $(0.1327)$, vibration pollution $(0.1026)$, water pollution (0.0943), as well as the results of previous studies on environmental pollution, indicate that the application of the entropy method to evaluation of environmental pollution caused by urban rail transit construction is scientific. The results also show that air pollution causes greater environmental pollution than vibration pollution.

Based on the entropy weight data of the Second-level index, the First-level index weights are obtained. The data shows that the natural environmental pollution caused by the construction of rail transit in the city centre $(0.5083)$ exceeds the sum of other indicators, i.e., the social environment, and the ecological environment. Natural environmental pollution, as a direct pollution object of track construction, has been relatively concerned by all parties. Its higher weight is in line with the actual situation. However, the social environmental pollution is also relatively high, indicating that with social development, people are increasingly paying attention to the urban environment. The requirements for the social environment are getting higher and higher. The construction of rail projects should pay attention to the social environmental pollution, reducing noise and vibration pollution. It also should consider urban landscaping, which effectively avoids unnecessary impacts on the project due to pollution to the social environment. The low weight of the ecological environment means that the construction of rail transit in the city centre relatively weakens the ecological damage, and the energy of the project in this regard may be weak.

\section{Environmental Pollution Assessment of XA-XDM Project by Combining Weight Method}

The combination weight method to determine the emergency capability index score is similar to the entropy weight method. The row vector for all indicators of the XA-XDM project is calculated by $W \times R=R_{\text {row }}$, and the specific scores of each index are $R_{\text {final }}=R_{\text {row }} \times[100,80,60,40,20]^{\mathrm{T}}$, among which the environmental impact is 100 to 80 points, the stronger is 80 to 60 points, the general is 60 to 40 points, the weaker is 40 to 20 points, and the weak is 20 to 0 points. Combining the right of environmental pollution indicators, the specific score of each indicator is [41.6, 54.0, 55.4, 90.6, 81.6, 84.3, $73.2,75.0,80.0,79.0,72.0]$, and further calculations based on the weight of the indicators were made to investigate the environmental pollution impact of the XA-XDM project. The evaluation score is 76.5. The evaluation results show that the XA-XDM project has a strong impact on environmental pollution. During the construction process, attention should be paid to the prevention, control and monitoring of various pollution indicators to reduce environmental pollution and achieve green construction. 


\section{CONCLUSION}

Aiming at evaluation of the environmental pollution caused by urban rail transit construction, an environmental impact assessment index system for urban rail transit construction was constructed by using the literature research method, and the entropy method was used to evaluate the pollution of the XA-XDM project construction on the urban environmental pollution, and the following conclusions are obtained:

1. An environmental impact assessment index system for urban rail transit construction is established, which fully summarizes the environmental pollution caused by rail construction, and provides a certain reference for subsequent research on environmental pollution caused by urban construction.

2. The entropy weight method is used to evaluate the environmental pollution caused by urban rail transit construction, and the weight of each pollution indicator is determined based on the results of quantitative analysis. The weighted result is in accordance with the law of previous research results, indicating that the entropy weight method is feasible to evaluate the environmental pollution of urban rail transit construction by law.

3. The environmental pollution impact assessment score of the XA-XDM project is 76.5. This result indicates that the XA-XDM project has a strong impact on environmental pollution. The construction of rail transit in the centre of the city should focus on indicators such as land subsidence, air pollution, and vibration pollution. Meanwhile, the protection of the urban landscape should not be neglected during track construction.

\section{REFERENCES}

Guan, L. 2018. Environmental Impact Assessment of Urban Rail Transit: Taking Xiaodongmen Station of Wuhan Rail Transit Line 7 as an example. World of Transportation, (21): 178-180.

Hala, A., Vasiliki, K. and Konstantinos, E. 2015. Developing Emission Factors of Fugitive Particulate Matter Emissions for Construction Sites in the Middle East Area. International Journal of Environmental, Chemical, Ecological, Geological and Geophysical Engineering, 9(2): 50-54.

Haron, Z., Yahya, K. and Mohamad, M.I. 2009. Probability approach for prediction of construction site noise. Journal of Asian Architecture and Building Engineering, 8(2): 571-577.

Hu, M.Q., Liu, M., You, D. and Zhang, Y. 2020. Influence of train arrival characteristics on unorganized ventilation in underground subway station with platform screen doors. Journal of Wind Engineering and Industrial Aerodynamics, 198, p.104089.
Huang, Y.H., Tian, G., Qin, J.P., Li, G. and Yan, B.L. 2007. Research on the characteristics of dust pollution in different construction stages. Environmental Science, (12): 2885-2888.

Li, X.D., Su, S., Huang, T.J. and Lin, Y. 2014. Comparative study on dust monitoring during earthwork and main structure construction. China Safety Science Journal, 24 (5): 126-131.

Liu, H.W. 2005. Pollution and control of construction noise. Petrochemical Environmental Protection, 28(4): 43-45.

Lu, L. and Liu, C.Y. 2021. Research on Airport Comprehensive Evaluation Model Based on Entropy Weight Method. Aeronautical Computing Technology, 51 (01): 64-66.

Meng, Y. P. and Xu, L.H. 2016. Numerical simulation study of ground settlement caused by subway tunnel excavation. Journal of Anhui Jianzhu University, 24 (3): 8-11.

Ministry of Environmental Protection of the People's Republic of China. 2018. China Environmental Noise Pollution Prevention and Control Report, available at http://www.mee.gov.cn/hjzl/sthjzk/hjzywr/.

Wang, P., Cao, J., Shen, Z.X., Han, Y.M., Lee, S.C., Huang, Y., Zhu, C.S., Wang, Q.Y., Xu, H.M. and Huang, R.J. 2015. Spatial and seasonal variations of PM2.5 mass and species during 2010 in Xi' an, China. Science of the Total Environment, 508: 477-487.

Wang, R., Zou X., Cheng H., Wu, X., Zhang, C. and Kang, L. 2015. Spatial distribution and source apportionment of atmospheric dust fall at Beijing during spring of 2008-2009. Environmental Science \& Pollution Research International, 22 (5):3547-57.

Wang, Y., Wei, J.S., Li, X.T., Bai, Y. and Wen, X.C. 2018. Comparison and enlightenment of environmental noise monitoring methods at home and abroad. China Environmental Monitoring, 34 (4): 150-154.

Wang, Y.Z. 2019. Research on the impact of urban rail transit on urban development and environment. Engineering Construction and Design, (5): 140-141.

Xue, Y. F., Zhou, Z., Huang, Y.H., Wang, K., Nie, T., Nie, L., Qin, J.P. 2017. Characteristics of fugitive dust emissions from building construction in Beijing. Environmental Science, 38 (6): 2231-2237.

Xue, X.F., Liu, H. and Wen M.Y. 2018. The environmental impact of urban rail transit construction. Qinghai Transportation Science and Technology, (5): 18-19.

Yang, F.L., Liu, Y.L. and Hu, B. 2013. Numerical simulation study on ground settlement caused by excavation of Wuhan subway tunnel. Journal of Engineering Geology, 21(1): 85-91.

Yang, X.X. 2011. Urban traffic noise and its hazards. Frontier Science, 5 (2): 21-28.

Zhang, H.Y., Zhang, W.L. and Guan, Y. 2020. Research on environmental impact assessment of hydropower projects based on probability language close to entropy. Mathematics in Practice and Knowledge, 50(17): 271-278.

Zhang, Q. 2013. Research on the noise coupling effect of simultaneous operation of multiple machines on the construction site. Building Construction, 35(9): 859-861.

Zhang, Z. W. 2021. Numerical simulation study on the environmental impact of the construction team of urban rail transit station. Anhui Architecture, 28(1): 161-163.

Zhu, Z.L. 2018. Research on the environmental impact and management status of domestic urban rail transit. Railway Communication and Signal Engineering Technology, 15 (10): 101-104. 